\title{
IMPACT AND PARTICLE VIBRATION ABSORBERS OPTIMAL DESIGN*
}

\author{
Volodymyr Snitynskyy ${ }^{1}$, Ivan Kernytskyy $₫ 2$, Bohdan Diveyev³ ${ }^{3}$ Orest Horbay ${ }^{3}$, \\ Petro Koruniak', Ruslan Humenyuk', Tetiana Kokhana' ${ }^{1}$
}

${ }^{1}$ Faculty of Mechanical and Power Engineering, Lviv National Agrarian University

${ }^{2}$ Institute of Civil Engineering, Warsaw University of Life Sciences - SGGW

${ }^{3}$ Institute of Engineering Mechanics and Transport, Lviv Polytechnic National University

\begin{abstract}
The paper contemplates the provision of impact or particle dynamic vibration absorber (DVA). An efficient numerical approach based on the theoretical-experimental method is proposed to maximize the minimal damping of modes in a prescribed frequency range for general viscous tuned-mass systems. Methods of decomposition and numerical synthesis on the basis of adaptive schemes are considered. The influence of dynamic vibration absorbers and basic design elastic and damping properties is under discussion. Compact buffered impact absorbers are analysed. One task of this work is to analyse parameters identification of the dynamic vibration absorber and the basic structure. The work focused on a single degree of order (SDOF) system which is equivalent to particle DVA. The simulation provides a close agreement with the measurements over various entire frequency ranges, which means the SDOF is simple yet easy to calculate the damped motion, compared with the experimental results of particle DVA. Examples of the attachment of particle DVA's and elongated element with multi-mass impact DVA's are offered. The paper contemplates the provision of the impact multi-mass DVA's with masses collisions and traction for additional damping. A technique is developed to give the optimal DVA's for the elimination of excessive vibration in harmonic and impact loaded systems.
\end{abstract}

Key words: dynamic vibration absorber, particle-based damping system, buffered absorber, optimization, design

\section{INTRODUCTION}

Impact and particle dampers have been extensively studied and investigated to counter vibrations at industrial machinery and structural systems. This is due to the fact that they are simple in design and easy to implement. In the article the methods of calculation and optimization of much of mass shock type and particle DVA's are examined for diminishing of vibration at small frequencies of vibrations of base construction. The algorithms of diminishing of vibration of base construction are got. Absorption of energy is taken into account for an account

\footnotetext{
* Text was formatted in one-column page style due to complexity of the article.

Volodymyr Snitynskyy https://orcid.org/0000-0001-9633-1004; Ivan Kernytskyy https://orcid.org/0000-0001-6084-1774; Bohdan Diveyev https://orcid.org/0000-0001-5184-499X; Ruslan Humenyuk https://orcid.org/0000-0001-7511-3673; Tetiana Kokhana https:// orcid.org/0000-0002-2909-6419

凶ivankernytskyy@ukr.net
} 
to the movement of the rolling masses on the curved surface, to the blow of the masses to the resilient elastic barriers and the masses impacts between itself.

The purpose of our study is the elaboration of a stable identification and optimization algorithm allowing one to uniquely determine the DVA parameters, including the basic system ones. The problem of identification necessarily includes the planning of experiments, the construction of a calculation model, and the identification schemes themselves. In this study, the construction of the model is considered in two plans: first, adaptation of the model to the kind of specimens and experimental equipment employed and, second, adaptation of the model to the identification scheme. The reliability of the results obtained was estimated by analysing the robustness of the calculation schemes suggested.

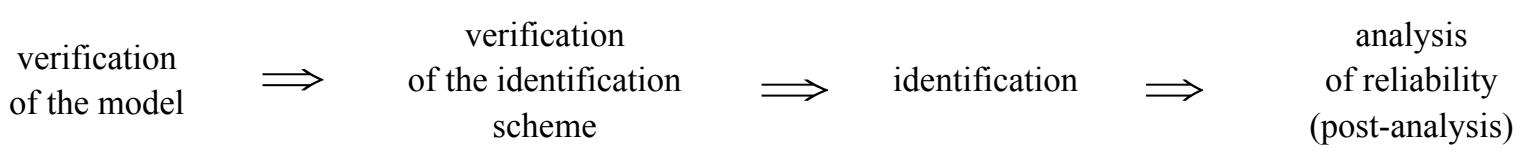

The dynamic response and performance of single unit impact dampers has been studied extensively. Pioneering research was conducted by Paget (1937). Further research (Grubin, 1956) determined the existence of the optimal distances between the primary mass and the auxiliary mass for the impact damper. Masri (1968) presented a piecewise analytical solution for the dynamics of an impact damper, and determined that the most effective damping condition occurred with two symmetric collisions per cycle. Bagpat and Sankar (1985), and Ema and Marui (1994) provided further the relation between the coefficient of restitution and damping ratio of the impact and found the optimum damping effect by changing the mass ratio of the damper to the structure. Moreover, many kinds of impact dampers have since been introduced, among them with resilient buffers (Chen \& Wang, 2003; Li \& Darby, 2006; Park, Wang \& Crocker, 2009). Friend and Kinra (2000), and Fang and Tang (2006) presented the particle DVA's. The effects of various system parameters, including filled mass ratio (Inoue, Yokomich \& Hiraki, 2014) under harmonic force excitation when the investigated use a SDOF structure (Marhadi \& Kinra, 2005, Saeki, 2005, Shah et al., 2009).

Detailed experiments with a horizontal impact damper explain the general performance and the resonance vibration of the integrated system, which occurs at a frequency, which is different from the original resonance frequency. The numerical schemes row for the complex vibro-loaded construction and methods of decomposition and the numerical schemes synthesis are considered in our paper on the basis of methods of modal synthesis (Kernytskyy, Diveyev, Pankevych \& Kernytskyy, 2006; Cherchyk, Diveyev, Martyn \& Sava, 2014; Diveyev, Vikovych, Martyn \& Dorosh, 2015; Diveyev, 2017).

\section{MATERIAL AND METHODS}

\section{Impact masses DVA}

Let us consider condensed model of impact masses DVA - primary system. In Figure 1 the impact mass type DVA is presented: an additional impact masses in container with elastic barrier elements and boundary elements non-linear contact forces:

$$
F_{1}\left(u_{1}-u_{X_{1}}\right), \quad F_{3}\left(u_{1}-u_{X_{3}}\right)
$$

Consider now the DVA with three different impact masses in one container (Fig. 1). 
a

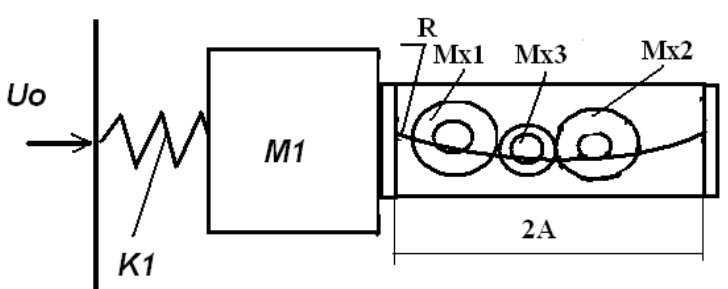

b

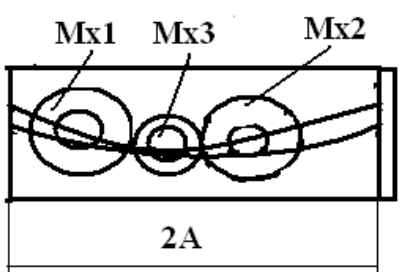

Fig. 1. DVA with three different impact masses: $a$ - one radiuses of sending plates; $b$ - two different radiuses (two curved base plates for every rolling masses)

The system of equations is now:

$$
\begin{aligned}
& m_{1} \frac{d^{2} u_{1}}{d t^{2}}+k_{1}\left(u_{1}-u_{0}\right)+k_{A}\left(u_{1}-u_{A}\right)-\frac{m_{X_{1}}}{R_{X_{1}}}\left(u_{X_{1}}-u_{A}\right)+k_{X_{1}} F_{1}\left(u_{1}-u_{X_{1}}\right)-\ldots \\
& -\frac{m_{X N}}{R_{X N}}\left(u_{X N}-u_{A}\right)+k_{X N} F_{N}\left(u_{1}-u_{X N}\right)=F(t) \\
& m_{X_{1}} \frac{d^{2} u_{X_{1}}}{d t^{2}}+\frac{m_{X_{1}}}{R_{X_{1}}}\left(u_{X_{1}}-u_{A}\right)-k_{X_{1}} F_{1}\left(u_{1}-u_{X_{1}}\right)+F_{12}\left(u_{X_{1}}, u_{X_{2}}\right)+F_{13}\left(u_{X_{1}}, u_{X_{3}}\right)=0 \\
& m_{X_{2}} \frac{d^{2} u_{X_{2}}}{d t^{2}}+\frac{m_{X_{2}}}{R_{X}}\left(u_{X N}-u_{A}\right)-k_{X} F_{N}\left(u_{1}-u_{X_{2}}\right)-F_{12}\left(u_{X_{1}}, u_{X_{2}}\right)+F_{23}\left(u_{X_{2}}, u_{X_{3}}\right)=0 \\
& m_{X_{3}} \frac{d^{2} u_{X_{3}}}{d t^{2}}+\frac{m_{X_{2}}}{R_{X}}\left(u_{X N}-u_{A}\right)-F_{13}\left(u_{X_{1}}, u_{X_{3}}\right)-F_{23}\left(u_{X_{2}}, u_{X_{3}}\right)=0
\end{aligned}
$$

Three DVA's masses are considered. Parameters $m_{1}, k_{1}$ of the prime system may be found by means of FEM or experimentally (Kernytskyy, Diveyev, Stukalets, Horbaj \& Berezovetskyi, 2018). The non-linear functions are:

$$
F_{i}=-K_{v i}\left(x_{i}-A_{i}\right),\left|x_{x}\right|>A_{i}, F_{i}=0,\left|x_{i}\right|<A_{i}, F(t)=a \sin (\omega t)
$$

where:

$A$ - clearance;

$K_{v i}$ - boundary elements rigidity.

The non-linear functions $F_{13}\left(u x_{1}, u x_{3}\right), F_{23}\left(u x_{2}, u x_{3}\right)$ of DVA's masses interaction may be defined analogously:

$$
\begin{array}{cccc}
F_{13}=F_{13}\left(x_{1}-x_{3}\right) & \left|x_{1}-x_{3}\right|<R_{1}+R_{3}, & F_{13}=0 & \left|x_{1}-x_{3}\right|>R_{1}+R_{3} \\
F_{23}=F_{13}\left(x_{2}-x_{3}\right) & \left|x_{2}-x_{3}\right|<R_{2}+R_{3}, & F_{23}=0 & \left|x_{2}-x_{3}\right|>R_{2}+R_{3}
\end{array}
$$




\section{DVA with particle damper}

There have been recent studies that employed the discrete element method (DEM) for granular damping analysis that can keep track of the motions of an assembly of granules through direct integration of the dynamic equations of granules. This is due to the rapid improvements in computational hardware and software over the years, resulting in simulation of thousands of granular particles. Ideally, the analytical design method would include a first-order model which can be used for preliminary design purposes and design studies, along with a DEM model implementation for more sophisticated design and analysis, and final design validation. The initial first order model has focused on a SDOF system with an equivalent single particle impactor (granular bed / lumped mass). Such approach is difficult enough. It requires not only difficult calculations but also determination of many parameters of micro-impacts and micro-sliding particles. That is why in this article we will apply the same one mass model (SDOF) for particles in a container. The parameters of this model were determined on the basis of row of experiments (Inoue et al., 2014). In Figure 2a the scheme of pump structure with two particle absorbers attachment is presented.

a

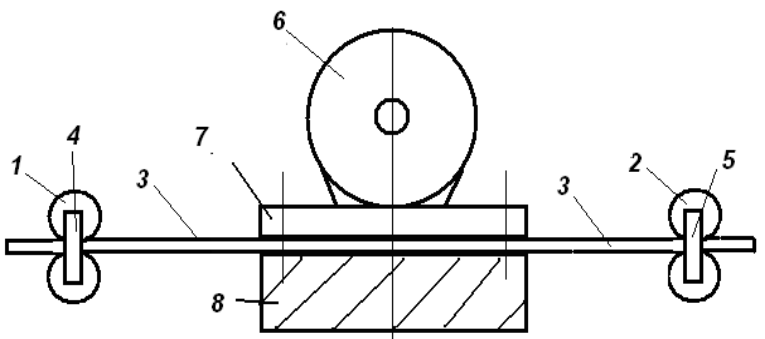

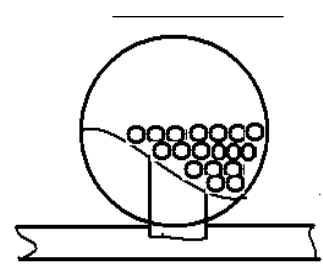

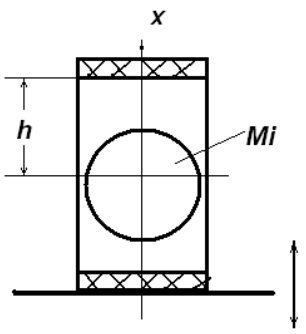

Fig. 2. a - pump - DVA scheme (1, 2, 3, 4, 5-DVA's, 6, 7 - pump and pump base, 8 - pump foundation); $b$ - DVA filled container; c - container model

In this paper the condensed numerical model is proposed. The system of equations in the condensed rangy is obtained. For the particle dynamic modelling (Fig. 2b) the condensed impact mass damper was applied (Fig. 2c). The equations for the impact mass are:

$$
\begin{aligned}
& m_{i} \frac{d^{2} w_{i}}{d t^{2}}+C_{i} \frac{d w_{i}}{d t}+k_{G}(x)\left(w_{i}-w_{0}\right)+C_{G}(x)\left(\frac{d w_{i}}{d t}-\frac{d w_{0}}{d t}\right)=0,\left|w_{i}-w_{0}\right|>|h-R| \\
& m_{i} \frac{d^{2} w_{i}}{d t^{2}}+C_{i} \frac{d w_{i}}{d t}=0,\left|w_{i}-w_{0}\right| \leq|h-R|
\end{aligned}
$$

where:

$m_{i}$ - particle mass;

$C_{i}$ - damping viscoelastic coefficient, modelling particle traction in container;

$K_{G}-$ rigid coefficient;

$C_{G}-$ viscoelastic coefficient for particle elastic impact modelling;

$w_{i}$ - impact mass displacement.

\section{Parameter identification}

Model parameters (system DVA-basis) can be identified on the basis of experimental research. For identifying parameters of models of dynamics of structures numerous methods are known. They can also be applied to the model DVA-basis. However, simplistic models can be used to parameterize this model. After all, these models 
are mainly aimed at quenching vibration at relatively low frequencies. At these frequencies, which lie in the vicinity of the first resonance frequencies, the greatest amplitudes of oscillations are observed. Therefore, for modelling a system, it is often enough to consider only the first frequencies and forms of resonant oscillations. Here again there can be two ways. The first one is calculated, based, for example, on the most common method of finite element (FEM). However, not for any construction, this method can be easily applied. Take, for example, the pump that is considered here. Here it is necessary to consider both the design of the pump, and the foundation, and collectors. For this system, an experimental method is proposed here that takes into account the interaction of the structure with the DVA.

\section{Identification of the parameters of the longitudinal design (boom sprayer rod wings)}

For the study of complex structures with DVA, simplified models, in the first place of the basic design, are found to be effective. Often it is enough, especially for an elongated element, to consider only the first form of oscillation in the vicinity of the first resonant frequency. These elongated element parameters can be obtained in many ways using the FEM. As an example of the application of such a technique, consider the optimal design of the DVA to reduce the horizontal vibrations of the spray rod (Fig. 3a). Taking into account that both the first resonance frequency of the rod wings and the peak of external perturbation are in the low-frequency range, consider the single-mass model of the rod wings (Fig. 3b). This is the mass on the weightless rod (a), equivalent to the classical single-mass model - the mass on the spring (Fig. 3b). The calculation model is described by the following differential equation:

$$
m \ddot{w}+k D \dot{w}+k w=F
$$

where:

$k$ - appropriate stiffness;

$D$ - coefficient of viscous damping;

$w$ - displacement;

$F$ - perturbation.

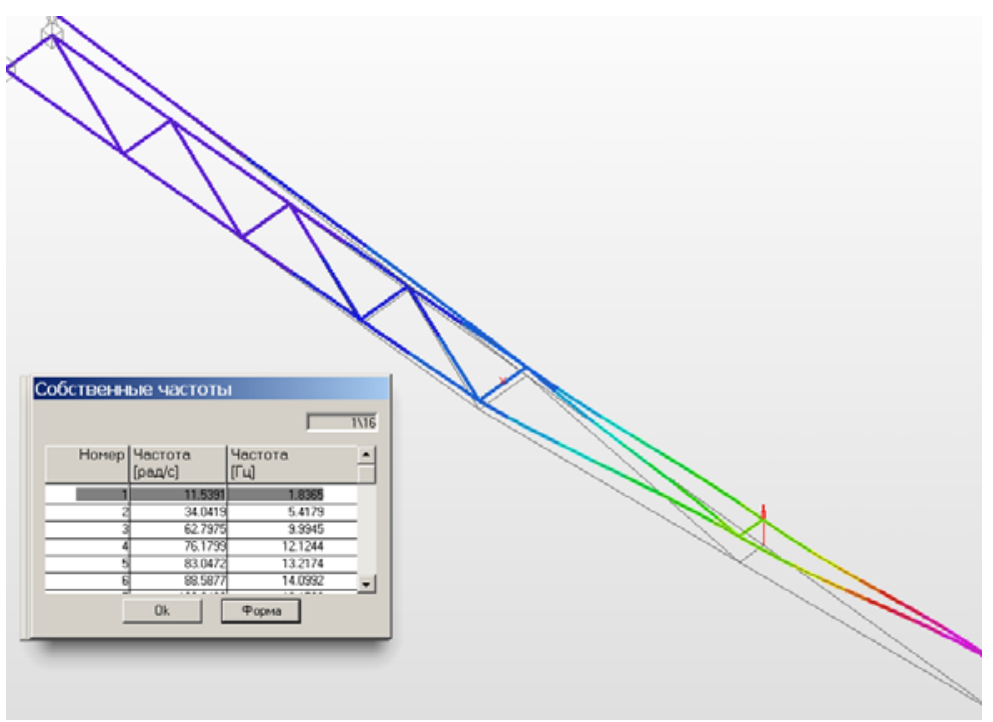

Fig. 3. $a$ - the first form of fluctuations of the farm; $b$ - single-mass model of the wings rod 
Parameters $m, k, D$ are unknown. Define $m, k$ based on the resonance frequency and rigidity found above. Rigidity $k$ is determined on the basis of FEM:

$$
k=\frac{F}{\Delta} \approx \frac{1,000}{0.295} \approx 3,390 \mathrm{~N} \cdot \mathrm{m}^{-1}
$$

We determine the mass on the basis by the formula:

$$
m=\frac{k}{\omega^{2}} \approx \frac{3,390}{11.54^{2}} \approx 25.45 \mathrm{~kg}
$$

The mass in the model is three times smaller than the weight of the rod wing (Fig. 3a).

\section{Identification of water pump parameters}

Although some parameters of DVA and pump can be determined by experiments, but some, such as basic system mass $m_{1}$ remains unknown in Eq. (1). For a more precise definition of the model parameters several additional experiments were conducted (for the definition of parameters $m_{1}, k_{1}$ - mass and stiffness of the primary system). At the same time DVA parameters $m_{A}, k_{A}$ require refinement. Although they can be calculated more accurately than the basic parameters of the system, yet it takes a lot of effort both in determining of the elastic properties of DVA and DVA clamping plate. Although you can conduct a detailed theoretical analysis, a series of simple experiments can quite accurately determine these parameters as integrated value included in the system of Eqs. (2)-(4). Originally let us show the correctness of these schemes. Performing for this series of experiments: kinematical perturbation DVA for its different masses (see diagram of the numerical experiment - Fig. 5):

$$
\begin{aligned}
& R=\left|f\left(m_{10}, k_{10}\right)-f\left(m_{1 i}, k_{1 i}\right)\right| \\
& m_{1 i}=m_{10}\left(i-\frac{N}{2}\right), i=1, \ldots, N \\
& k_{1 i}=k_{10}\left(i-\frac{N}{2}\right), i=1, \ldots, N
\end{aligned}
$$

As the device is designed to test, we are using our DVA. Performing for this series of experiments: kinematical perturbation DVA for its different masses, values of first eigen-frequencies were obtained for different masses $m_{A}$ located at the edge of the DVA plate. We see that the basic system parameters are determined uniquely by combined map (Fig. 4c) of Fig. $4 \mathrm{a}$ and Fig. $4 \mathrm{~b}$. To determine all the parameters $k_{1}, m_{1}, m_{A}, k_{A}$ we should apply

a

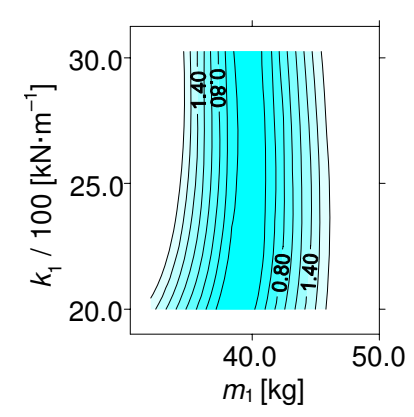

b

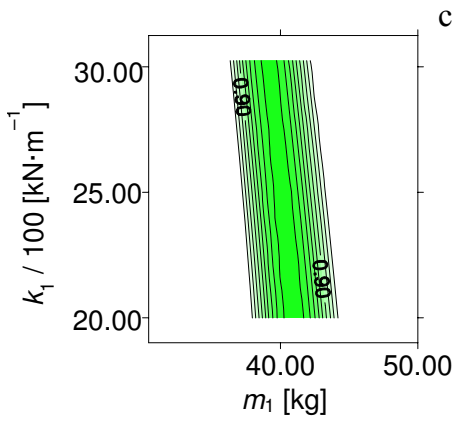

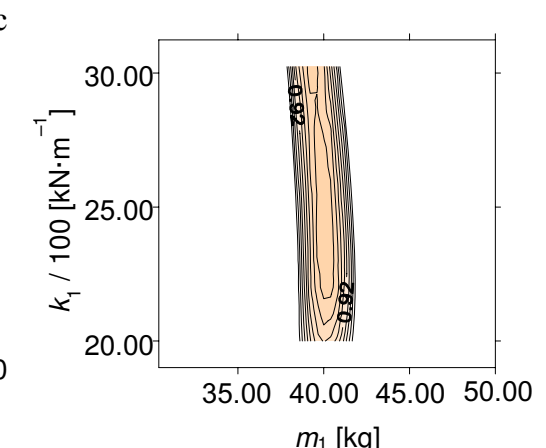

Fig. 4. The amount of frequencies deviation maps of DVA centred values depending on the change of parameters $k_{1}, m_{1}$ : $\mathrm{a}-$ for DVA weight $m_{1}=1.5 \mathrm{~kg} ; \mathrm{b}-m_{1}=3 \mathrm{~kg} ; \mathrm{c}-$ combined map of Fig. $4 \mathrm{a}$ and Fig. $4 \mathrm{~b}$ 
a genetic method to minimize the objective function $F_{c}=\sum_{i}\left|f_{T}\left(M_{i}\right)-f_{e}\left(M_{i}\right)\right|$, where: $f_{T}\left(M_{i}\right)=f_{T}\left(M_{i}, k_{1}\right.$, $\left.m_{A}, k_{A}\right)$ are theoretically obtained values of natural frequencies (first eigen-frequencies) and $f_{e}\left(M_{i}\right)$ are experimental values. The next values of first eigen-frequencies were obtained for the masses, located on verge of DVA's plate (the table).

Table. Eigen-frequencies for different DVA's masses

\begin{tabular}{ccccccc}
\hline$m[\mathrm{~kg}]$ & 0 & 0.669 & 1.100 & 1.521 & 1.881 & 3.115 \\
\hline$f[\mathrm{~Hz}]$ & 69 & 48 & 36 & 32.3 & 29.2 & 24.4 \\
\hline
\end{tabular}

We get the following values for the main components - pump in place joining DVA: $f_{1}=65.5 \mathrm{~Hz}$, $m_{1}=34.4 \mathrm{~kg}$. If the effect of the mass is difficult to track because of the complexity of the design of the pump, the oscillation frequency can be seen in paper by Diveyev (2017) for the shock disturbance. We see that it is in the vicinity of $65 \mathrm{~Hz}$ (as defined in theory). That is, the natural frequency of the main structure above the operating frequency of $50 \mathrm{~Hz}$. It gives information on what neighbouring eigen-frequencies DVA to seek optimum vibro-absorbtion at the operating frequency.

\section{RESULTS}

The most important functional feature of sprayers is the rapid and even spraying of drugs to the largest area without passing these drugs beyond the cultivated area. Especially important role is played by the parameters of such functional units as a rod with a suspension for rod sprayers. To reduce the amplitude of these oscillations, consider a boom sprayer with a dynamic vibration damper (Diveyev, 2017). Given that both the first resonance frequency of the rod wings and the peak of external perturbation are in the low-frequency range, consider the single-mass model of the rod wings. This mass is on a weightless rod (a), equivalent to the classical single-mass model - the weight on the spring (b). The calculation model is described by the following differential equation. Figure 5 shows results of single-mass DVA and three-mass DVA optimization. The experimental example of DVA (in natural size) is presented in Figure 6.

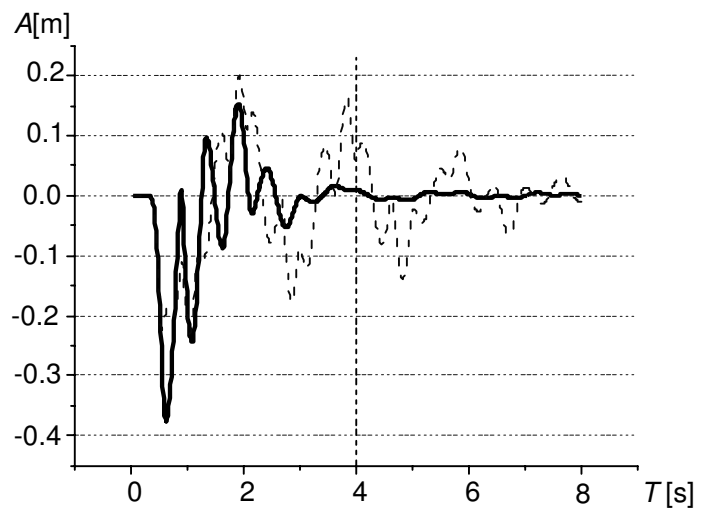

Fig. 5. Results of single-mass DVA (dash line) and three-mass DVA optimization

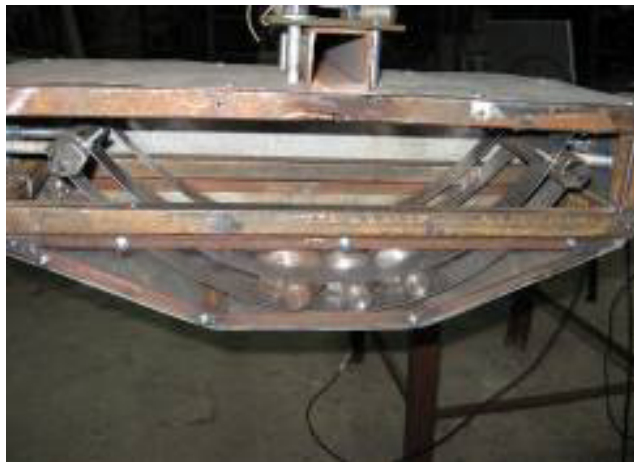

Fig. 6. The experimental example of DVA (in natural size) 
The single-mass DVA is worse than three-mass. The upper results in detail are presented by Diveyev (2017). The dynamic properties of boom wing were found by FEM. The particle DVA vibration by impulse kinematic loading is presented in Figure 7.

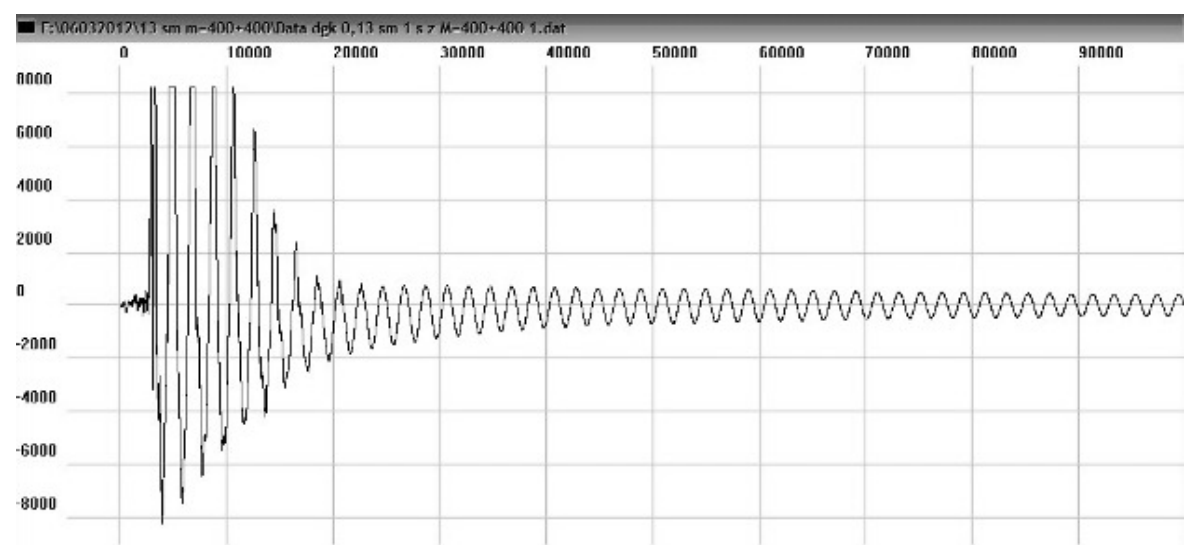

Fig. 7. DVA vibration by impulse kinematic loading

The experimental example of DVA (in natural size) is presented in Figure 8. Marhadi and Kinra (2005), and Saeki (2005), as well as Shah et al. (2009) proposed the condensed numerical model for particle ab-

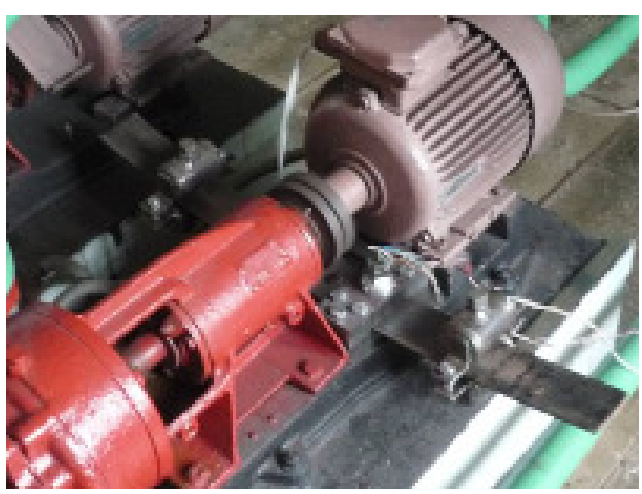

Fig. 8. Experimental setting for determination of dynamic properties of the DVA engine-pump system sorbers. On the basis of theoretical and experimental studies optimum parameters of DVA's was found. DVA natural frequency was measured. Then, based on measurements carried out with the included pump, optimization was carried. As can be seen in Figure 9, at a frequency close to the theoretical optimum, the amplitude of oscillation of the main structure is reduced by an order.

In this case the dynamic properties are difficult to obtain by FEM. Here the parameters of the model were determined on the basis of row of experiments, by the use of the same DVA with different masses. It should be noted that the optimal DVA frequency is another that the frequency of excitation.

a

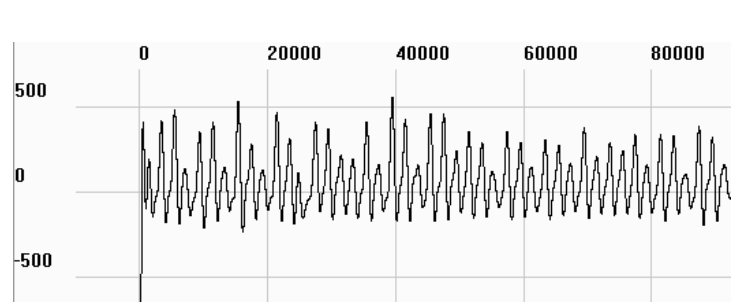

b

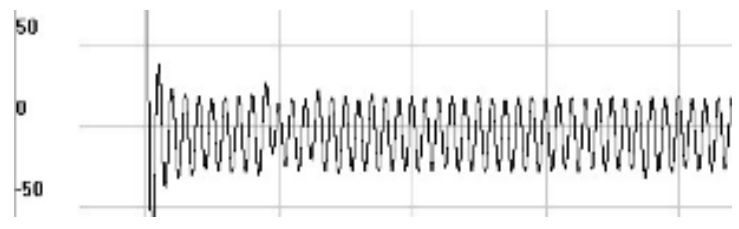

Fig. 9. Main structure acceleration at different DVA frequencies: $\mathrm{a}-f_{A}=46 \mathrm{~Hz} ; \mathrm{b}-f_{A}=47 \mathrm{~Hz}$ (optimal DVA frequency) 


\section{CONCLUSIONS}

In order to determine the optimal parameters of impact multi-mass DVA the complete modelling of dynamics of devices should be made. Paper deals with the new methods for the explicit determination of the frequency characteristics of dynamic vibration absorbers by impact and narrow frequency excitation. The new impact and particle vibro-absorbing elements are proposed. Few parameters numerical and schemes of vibration analysis are under discussion. Model parameters of DVA-basis system was identified on the basis of experimental research or FEM. The influence of geometric, elastic and damping properties of the basic construction and dynamic vibration absorbers are considered. The algorithms for vibration decreasing are received. The energy dissipation results from the exchange of momentum during impacts between the mass and the stops, mass friction during its motion and masses collegian as the structure vibrates. Examples of the attachment of particle DVA's for water pump and elongated element with multi mass impact DVA's are offered. It should be noted that by the optimal DVA's vibration decreasing are received (Figs. 5, 9). Only for large amplitude of vibration the damping in particle DVA is large (Fig. 7). Finally, present research develops the genetic algorithms for optimal design searching by discrete-continuum DVA's system - base system modelling.

\section{REFERENCES}

Bagpat, C. N. \& Sankar, S. (1985). Single unit impact damper in free and forced vibration. Journal of Sound and Vibration, 99, 85-94.

Chen, C. C. \& Wang, J. W. (2003). Free vibration analysis of a resilient impact damper. International Journal of Mechanical Science, 45, 589-604.

Cherchyk, H., Diveyev, B., Martyn, V. \& Sava, R. (2014). Parameters identification of particle vibration absorber for rotating machines. In M.J. Crocker (Ed.), Proceedings of 21st International Congress on Sound and Vibration (ICSV 21). International Institute of Acoustics and Vibration [electronic edition].

Diveyev, B. (2017). Impact and particle buffered vibration absorbers optimization and design. Ukrainian Journal of Mechanical Engineering and Material Science, 1 (2), 35-50.

Diveyev, B., Vikovych, I., Martyn, V. \& Dorosh, I. (2015). Optimization of the impact and particle vibration absorbers. In M.J. Crocker, M. Pawelczyk, F. Pedrielli, E. Carletti, S. Luzzi (Eds.), Proceedings of 22nd International Congress on Sound and Vibration (ICSV 22). International Institute of Acoustics and Vibration [electronic edition].

Ema, S. \& Marui, E. (1994). A fundamental study on impact dampers. International Journal of Machine Tools and Manufacturers, 34, 407-421.

Fang, X. \& Tang, J. (2006). Granular Damping in Forced Vibration: Qualitative and Quantitative Analyses. Journal of Vibration and Acoustics, 128 (4), 489-500.

Friend, R. D. \& Kinra, V. K. (2000). Particle Impact Damping. Journal of Sound and Vibration, 233 (1), $93-118$.

Grubin, C. (1956). On the theory of acceleration damper. Journal of Applied Mechanics, Transactions of the ASME, 78, 373-378.

Inoue, M., Yokomich, I. \& Hiraki, K. (2014). Design of Particle Granules Damper for Vertical Vibration with Approximate Analysis. Journal of System Design and Dynamics, 7 (4), 233-241.

Kernytskyy, I., Diveyev, B., Pankevych, B. \& Kernytskyy, N. (2006). Application of variation-analytical methods for rotating machine dynamics with absorber. Electronic Journal of Polish Agricultural Universities - Civil Engineering, 9 (4), 24. Retrieved from http:/www.ejpau.media.pl/articles/volume9/issue4/art-24.pdf

Kernytskyy, I., Diveyev, B., Stukalets, I., Horbaj, O. \& Berezovetskyi, S. (2018). Vibration absorber optimization for boom-sprayer. Scientific Review Engineering and Environmental Sciences, 27 (4), 504-515.

Li, K. \& Darby, A. P. (2006). An experimental investigation into the use of a buffered impact damper. Journal of Sound and Vibration, 291, 844-860.

Marhadi, K. S. \& Kinra, V. K. (2005). Particle impact damping: effect of mass ratio, material, and shape. Journal of Sound and Vibration, 283, 433-448. 
Masri, S. F. (1968). Analytical and experimental studies of multi-unit impact dampers. Journal of the Acoustical Society of America, 45, 1111-1117.

Paget, A. L. (1937). Vibration in steam turbine buckets and damping by impacts. Engineering, 143, 305-307.

Park, J., Wang, S. \& Crocker, M. J. (2009). Mass loaded resonance of a single unit impact damper caused by impacts and the resulting kinetic energy influx. Journal of Sound and Vibration, 323, 877-895.

Saeki, M. (2005). Analytical study of multi-particle damping. Journal of Sound and Vibration, 281, 1133-1144.

Shah, B. M., Pillet, D., Bai, X. M., Keer, L. M., Jane-Wang, Q. \& Snurr, R. Q. (2009). Construction and characterization of a particle-based thrust damping system. Journal of Sound and Vibration, 326, 489-502.

\section{DZIAŁANIE ORAZ OPTYMALNA KONSTRUKCJA DYNAMICZNEGO ABSORBERA DRGAŃ}

\section{STRESZCZENIE}

W artykule opisano działanie oraz optymalną konstrukcję dynamicznego absorbera drgań (DAD). W celu zmaksymalizowania parametrów amortyzacji drgań układu sprężystego zaproponowano wydajne podejście numeryczne wykorzystujące metodę teoretyczno-eksperymentalną. Rozpatrzono metody dekompozycji i syntezy numerycznej z zastosowaniem schematów adaptacyjnych. Przedyskutowano wpływ DAD na parametry sprężysto-tłumiące układu drgającego. Przeanalizowano działanie kompaktowego DAD. Jednym z zadań tej pracy jest analiza identyfikacji parametrów DAD i struktury podstawowej. Do analizy przyjęto model dynamiczny z jednym stopniem swobody, odpowiadający DAD działającemu na zasadzie particle damping. Modelowanie dostarcza rezultatów adekwatnych do danych eksperymentalnych. Opracowano różne konstrukcje DAD (jedno- i wielomasowe).

Słowa kluczowe: dynamiczny absorber drgań, układ amortyzacji drgań, pochłanianie drgań, optymalizacja, konstruowanie 